Check for updates

Cite this: RSC Adv., 2018, 8, 1803

\title{
Electrooxidation of $\mathrm{Pd}-\mathrm{Cu}$ NP loaded porous carbon derived from a $\mathrm{Cu}-\mathrm{MOF} \dagger$
}

\author{
Salma Mirza, ${ }^{\text {ab }}$ Hao Chen, ${ }^{a}$ Zhi-Gang Gu (D) *a and Jian Zhang (D) a
}

The development of new non-platinum catalysts for alcohol electrooxidation is of utmost importance. In this work, a bimetallic $\mathrm{Pd}$-Cu loaded porous carbon material was first synthesized from a Cu-based metal-organic framework (MOF). The $\mathrm{Cu}$ loaded porous carbon was pre-synthesized through calcinating the $\mathrm{Cu}$-based MOF under a $\mathrm{N}_{2}$ atmosphere. After loading Pd onto the precursor and heating, $\mathrm{Pd}-\mathrm{Cu}$ loaded porous carbon $(\mathrm{Pd}-\mathrm{Cu} / \mathrm{C}$ ) was obtained for alcohol electrooxidation. Electrooxidation experiments revealed that this $\mathrm{Pd}-\mathrm{Cu}$ bimetal loaded porous carbon assisted steady state electrolysis for alcohol oxidation in alkaline media. Moreover, different alcohols were electrooxidated using the present electrocatalyst for the purposes of discussing the oxidation mechanism. This electrooxidation study of $\mathrm{Pd}-\mathrm{Cu} / \mathrm{C}$ derived from a MOF demonstrates a good understanding of the electrooxidation of different alcohols, and provides useful guidance for developing new electrocatalyst materials for energy

Received 17th September 2017 Accepted 19th December 2017

DOI: $10.1039 / c 7 r a 10331 j$

rsc.li/rsc-advances conversion and electronic devices.
There is an immediate need to develop direct alcohol fuel cells (DAFCs), which have been proven to be a fine source of energy, which could probably replace fossil fuels use to fulfil global energy demand. As one of the most significant electrocatalytic procedures, the electrooxidation of alcohols is an important process in DAFCs, and has gathered much attention and is attractive, due to high power density output and low pollutant emissions. Generally, Pt based materials are the most common electrocatalysts for alcohol electrooxidation reactions. However, the high cost and limited supply of Pt severely restricts its commercial application. Therefore, the development of new efficient and inexpensive non-platinum alternative materials to Pt-based catalysts is of utmost importance.

Metal-organic frameworks (MOF) are assembled from metal ions linked by organic ligands, and are used in catalysis, guest molecule storage/separation, fluorescence, sensors and other devices. ${ }^{1-3}$ Due to their highly ordered porous structures and large surface areas, MOFs can also be used as templates/ precursors for preparing porous carbon materials through thermal treatment. ${ }^{4-8}$ Several MOF derived carbon materials with good electrical conductivity are reported to show effective electrocatalytic performance, ${ }^{9}$ such as in the oxygen evolution reaction (OER), ${ }^{10}$ hydrogen evolution reaction (HER), ${ }^{11}$ and oxygen reduction reaction (ORR). ${ }^{12}$ Recently, a zeolitic

${ }^{a}$ State Key Laboratory of Structural Chemistry, Fujian Institute of Research on the Structure of Matter, Chinese Academy of Sciences, Fuzhou, Fujian 350002, P. R. China. E-mail: zggu@firsm.ac.cn

${ }^{b}$ University of Chinese Academy of Sciences, Beijing, 100049, P. R. China

$\dagger$ Electronic supplementary information (ESI) available. See DOI: $10.1039 / \mathrm{c} 7 \mathrm{ra} 10331 \mathrm{j}$ imidazolate framework ZIF-8 was calcinated in order to prepare porous carbon with both micro- and meso-pores to support Pd electrocatalysts for methanol electrooxidation. ${ }^{13}$ Unfortunately, this could not efficiently limit the use of the noble metal, which gives challenges to scientists for further exploration.

It has been demonstrated that the alloying of noble metals with transition metals has been used for the enhancement of catalytic activity and reduction of cost, ${ }^{14}$ because of the low cost and relatively high abundance of transition metals. The use of alloyed metal, $\mathrm{Pd}-\mathrm{M}$ (where $\mathrm{M}$ is $\mathrm{Cu}$, Co or $\mathrm{Ni}$ ), binary electrocatalysts has been reported for effectively improving the catalytic properties. ${ }^{15-17}$ For this purpose, introducing a non-noble metal into a noble metal bimetallic system will fulfil the demand for a new catalyst and become an area of interest nowadays. The second metal (such as $\mathrm{Cu}$ ) will behave as a donor, while Pd has an empty d orbital to accept electrons, and it is assumed that its electronic properties will be more similar to Pt. ${ }^{18}$ Therefore, Pd-Cu bimetal loaded porous carbon derived from a Cu-MOF can provide a good electrocatalyst for alcohol oxidation.

In this work, as shown in Scheme 1, we have synthesized $\mathrm{Cu}$ loaded porous carbon through the direct carbonization of a porous $\mathrm{Cu}$ based MOF. After loading Pd onto the precursor and heating, $\mathrm{Pd}-\mathrm{Cu}$ bimetal loaded porous carbon $(\mathrm{Pd}-\mathrm{Cu} / \mathrm{C})$ was obtained. Chronoamperometric studies revealed that this $\mathrm{Pd}-\mathrm{Cu}$ bimetal loaded porous carbon assisted steady state electrolysis for alcohol oxidation in alkaline media. In addition, alcohols with different numbers of carbon atoms (such as ethanol, 1-propanol and 2-propanol) were also investigated for electrooxidation. It is important to note that the effectiveness of this bimetallic NP loaded carbon means that it can serve as 

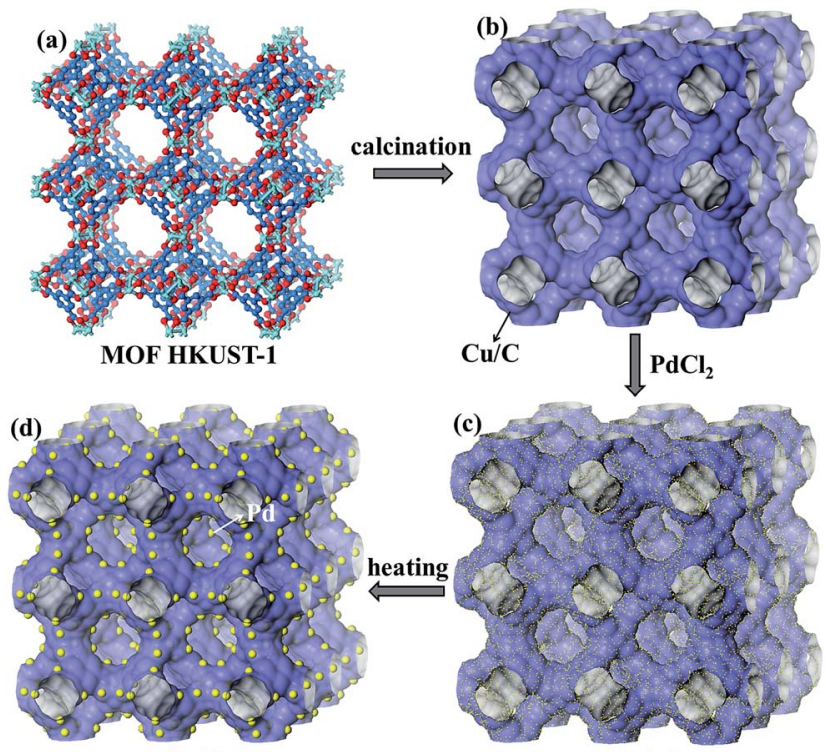

$\mathbf{P d}-\mathrm{Cu} / \mathrm{C}$

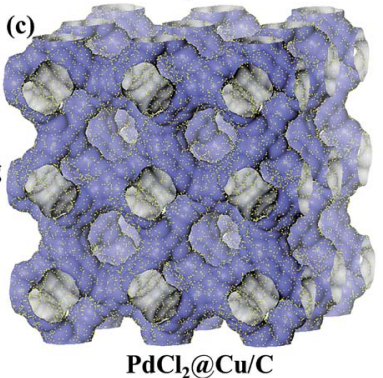

Scheme 1 The preparation procedure for $\mathrm{Pd}-\mathrm{Cu} / \mathrm{C}$ derived from HKUST-1 and $\mathrm{PdCl}_{2}$ : (a) MOF HKUST-1; (b) Cu/C calcinated from HKUST-1; (c) $\mathrm{PdCl}_{2}$ loaded on $\mathrm{Cu} / \mathrm{C}$; and (d) the $\mathrm{Pd}-\mathrm{Cu} / \mathrm{C}$ material.

a catalyst for the electrooxidation of low-molecular weight alcohols, which probably can be used as energy sources in portable electronic devices.

Here, a 3-D MOF, HKUST-1 (also called $\mathrm{Cu}_{3}(\mathrm{BTC})_{2}$, BTC $=$ 1,3,5-benzenetricarboxylate), was chosen as the precursor for preparing the $\mathrm{Cu} / \mathrm{C}$ material, due to the structure having high porosity and it being a rich $\mathrm{Cu}$ source. The as-synthesized HKUST- 1 was calcinated at $700{ }^{\circ} \mathrm{C}$ for $5 \mathrm{~h}$ under a $\mathrm{N}_{2}$ atmosphere, and the $\mathrm{Cu} / \mathrm{C}$ material was obtained. In addition, the guest species $\mathrm{PdCl}_{2}$ was loaded onto the calcinated HKUST-1 through immersing the pre-calcinated HKUST-1 into a $\mathrm{PdCl}_{2}$ ethanolic solution (1 mM) for $2 \mathrm{~h}$ (Scheme 1). The $\mathrm{PdCl}_{2}$ loaded $\mathrm{Cu} / \mathrm{C}\left(\mathrm{PdCl}_{2} @ \mathrm{Cu} / \mathrm{C}\right)$ was heated at $300{ }^{\circ} \mathrm{C}$ for $1 \mathrm{~h}$ under a $\mathrm{N}_{2}$ atmosphere. Finally, an alloy of $\mathrm{Pd}$ and $\mathrm{Cu}$ loaded porous carbon material $(\mathrm{Pd}-\mathrm{Cu} / \mathrm{C})$ was obtained and characterized through powder XRD, BET and XPS analyses.

The PXRD data (Fig. 1a) from as-synthesized HKUST-1 powder and the bimetallic Pd-Cu NP loaded carbon porous material derived from HKUST-1 show that the samples contain bimetallic palladium and copper mostly. The XRD peak appearing at $43.3^{\circ}$ corresponds to the (fcc) (111) facet plane of $\mathrm{Cu}$. Due to Pd being dispersed homogenously at a low concentration through the sample, the XRD pattern could not display the obvious peak from Pd. However, inductively coupled plasma emission spectroscopy (ICP) data (Table S1 $\dagger$ ) from the sample showed $0.76 \% \mathrm{Pd}$ and $36.68 \% \mathrm{Cu}$, indicating the existence of Pd and $\mathrm{Cu}$. The porosity of $\mathrm{Pd}-\mathrm{Cu} / \mathrm{C}$ was demonstrated through BET data, which shows $\mathrm{N}_{2}$ adsorption of $\sim 150 \mathrm{~cm}^{3} \mathrm{~g}^{-1}$. The Pd XPS spectrum showed two definite peaks at 335.5 and $341 \mathrm{eV}$, respectively assigned to $3 d_{5 / 2}$ and $3 d_{3 / 2}$ and matching well with $\mathrm{Pd}^{0}$. XPS peaks at 932.4 and $952.1 \mathrm{eV}$ indicate the valence states of $\mathrm{Cu}$ ions in the $\mathrm{Cu} 2 \mathrm{p}_{3 / 2}$ and $\mathrm{Cu} 2 \mathrm{p}_{1 / 2}$ orbitals in the $\mathrm{Pd}-\mathrm{Cu} / \mathrm{C}$
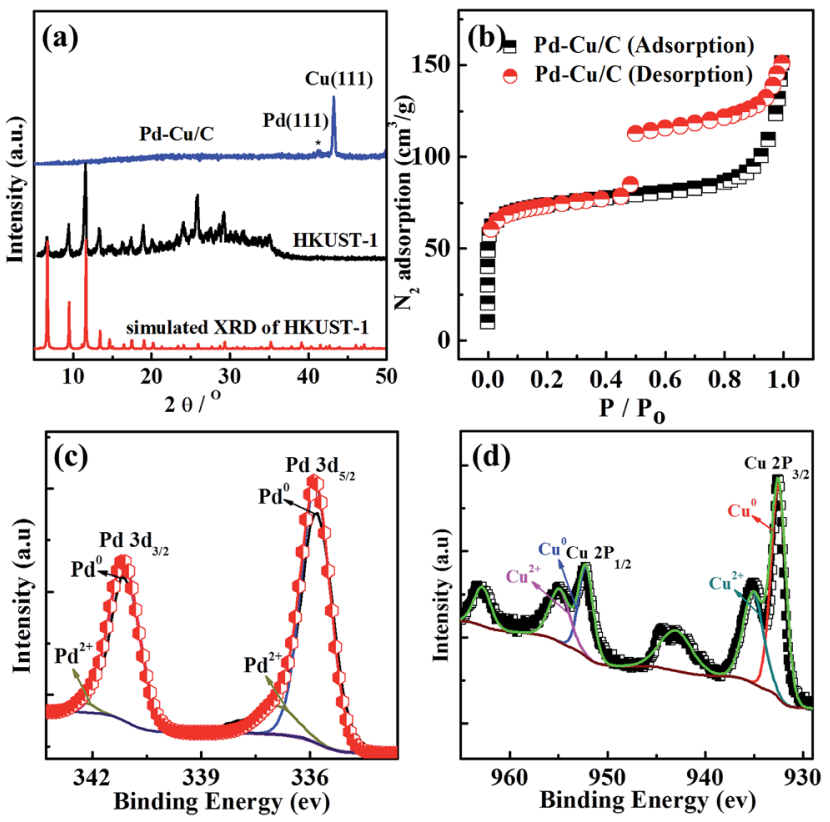

Fig. 1 (a) XRD data from HKUST-1 and Pd-Cu/C; (b) $\mathrm{N}_{2}$ sorption isotherms for $\mathrm{Pd}-\mathrm{Cu} / \mathrm{C}$; and XPS data from (c) $\mathrm{Pd}$ and (d) $\mathrm{Cu}$ in a sample of $\mathrm{Pd}-\mathrm{Cu} / \mathrm{C}$.

material. $\mathrm{Cu}^{2+}$ is present in the porous carbon material, with respective peaks at $933.7 \mathrm{eV}$ and $934.4 \mathrm{eV}$ from $\mathrm{CuO}$ and $\mathrm{Cu}(\mathrm{OH})_{2}$, with a prominent satellite observed in the $938-946 \mathrm{eV}$ range. A few $\mathrm{Pd}^{2+}$ ions also exist in the sample due the easy oxidation of the surface. The Raman spectrum of $\mathrm{Pd}-\mathrm{Cu} / \mathrm{C}$ (Fig. S4†) shows typical graphitic carbon. The results of the characterization studies clearly reveal that the nanoparticles have a Pd and $\mathrm{Cu}$ bimetallic nature.

SEM images with EDS (Fig. 2a and b) results show that the sample contained much more copper than palladium, which clearly suggests that the presence of copper in the sample would probably be the reason for the expected electrooxidation of alcohols. It could be possible to replace the use of high-cost Pd or Pt based catalysts. The morphology of the Pd-Cu NPs was further characterized via TEM imaging and TEM element mapping (Fig. 2c, d and S5†), demonstrating that the nano-sized NPs were dispersed homogeneously. The HR-TEM image in Fig. 2c gives insight into the bimetallic nature of the synthesized nanoparticles, with two noticeable lattice fringes $(0.225 \mathrm{~nm}$ for $\mathrm{Pd}(111)$ and $0.202 \mathrm{~nm}$ for $\mathrm{Cu}(111))$. The mean size of the Pd-Cu NPs was $7.38 \mathrm{~nm}$, as shown in Fig. 2d. The homogenous distribution, with well-defined bimetallic $\mathrm{Pd}-\mathrm{Cu}$ based carbon material, was good for the electrooxidation of alcohols. The electrochemical active surface area (ECSA) for Pd$\mathrm{Cu} / \mathrm{C}$ was high compared with commercial $\mathrm{Pd} / \mathrm{C}$, which suggested that the synthesized $\mathrm{Pd}-\mathrm{Cu} / \mathrm{C}$ has ample available surface area, mainly because of synergistic effects from the $\mathrm{Cu}$ MOF based carbon material and the morphology of the electrocatalyst.

In Fig. 3, CV profiles for commercial $\mathrm{Pd} / \mathrm{C}$ and the presented $\mathrm{Pd}-\mathrm{Cu} / \mathrm{C}$ show two distinct peaks (forward (iF) and backward 

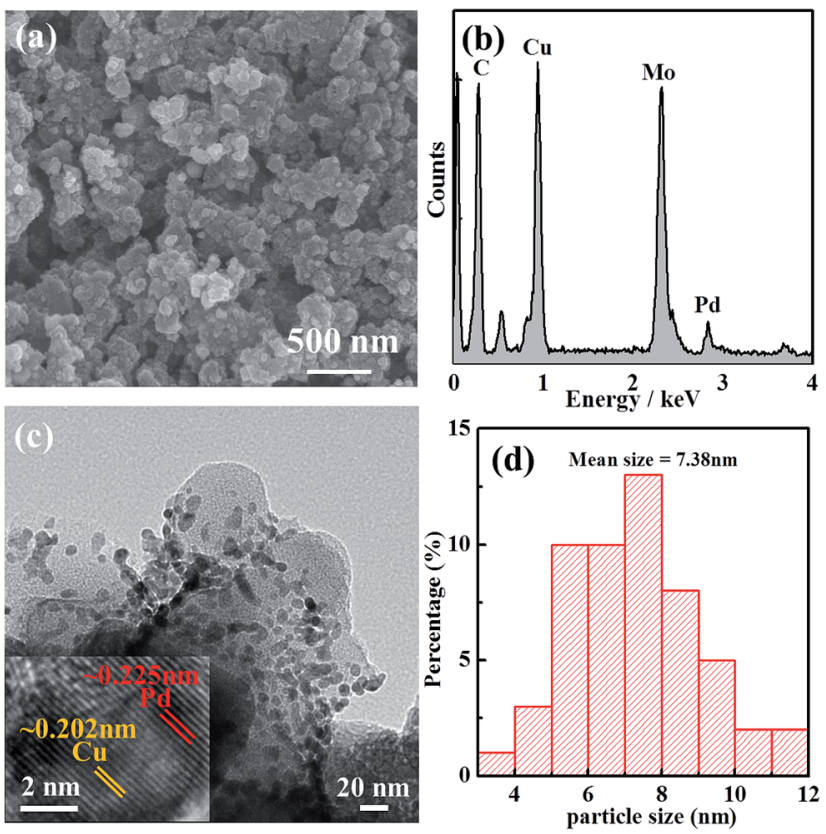

Fig. 2 (a) SEM image of and (b) EDS data from Pd-Cu/C; (c) a TEM image of $\mathrm{Pd}-\mathrm{Cu}$ NPs in the hybrid carbon material; and (d) the size distribution of the Pd-Cu NPs.

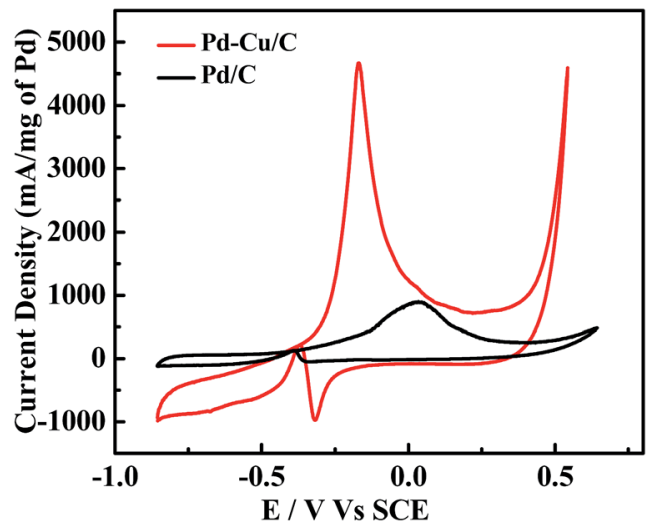

Fig. $3 \mathrm{CV}$ curves from $\mathrm{Pd} / \mathrm{C}$ and $\mathrm{Pd}-\mathrm{Cu} / \mathrm{C}$ electrocatalysts during $\mathrm{CH}_{3} \mathrm{OH}(1 \mathrm{M})$ oxidation in $1 \mathrm{M} \mathrm{KOH}$ solution, at a scan rate of $50 \mathrm{mV} \mathrm{s}^{-1}$, at room temperature.

(iB) peaks) during the oxidation of methanol-containing $1 \mathrm{M}$ $\mathrm{KOH}$ solution. The peak at $-0.37 \mathrm{~V}$ indicates the oxidation of aforementioned carbonaceous species, such as $\mathrm{Pd}-\mathrm{CO}_{\mathrm{ads}}$, along with newly formed alcohol adsorbates, following the removal of surface intermediates at lower potentials. ${ }^{19}$ For the forward peak potential, a shift in the if value is observed, mainly because of $\mathrm{Cu}$ existing with $\mathrm{Pd}$ in the material. This results in the oxidation of poisonous species, such as Pd adsorbed CO, at higher potentials ${ }^{20}$ leading to such high activity. ATR-IR (Fig. S7†) and GC analyses (Fig. S8 $\dagger$ ) show the methanol oxidation reaction (MOR) pathway during the formation of the final $\mathrm{CO}_{2}$ product. The catalytic activity of $\mathrm{Pd}-\mathrm{Cu} / \mathrm{C}$ is found to be $\sim 13$ times higher than commercial $\mathrm{Pd} / \mathrm{C}$ for methanol oxidation, demonstrating that the presence of $\mathrm{Cu}$ with $\mathrm{Pd}$ in $\mathrm{Pd}-$
$\mathrm{Cu}$ based catalysts increases $\mathrm{CO}$ oxidation because of a strong binding ability. $\mathrm{Cu}$ binds to $\mathrm{CO}$ more strongly than $\mathrm{Pd}$, as a result of electronic structure differences, ${ }^{21,22}$ thus preventing the electrode from undergoing CO poisoning, a major issue for Pd-based catalysts during the methanol oxidation reaction (MOR). The mechanism of methanol oxidation is shown in the ESI (eqn (8)-(10)). $\dagger$ The high iF value for $\mathrm{Pd}-\mathrm{Cu} / \mathrm{C}$ can be ascribed to the fast formation of reactive intermediates, such as $\mathrm{Pd}-\mathrm{CH}_{2} \mathrm{OH}, \quad \mathrm{Pd}-\mathrm{COOH}, \quad \mathrm{Pd}-\mathrm{H}, \quad \mathrm{Pd}-(\mathrm{CHO})_{\text {ads }}$, and $\mathrm{Pd}-$ $(\mathrm{COOH})_{\mathrm{ads} s}{ }^{23-25}$ The removal of these intermediates is necessary for a high current density. Furthermore, formaldehyde (HCHO), formic acid $(\mathrm{HCOOH})$ and $\mathrm{CO}_{2}$ would be the final products in the MOR. ${ }^{26,27} \mathrm{Pd}-\mathrm{Cu} / \mathrm{C}$ has good catalytic activity for the MOR, leading to further investigation into the electrooxidation of different alcohols, such as ethanol, 1-propanol, and 2-propanol (Fig. 4 and Table S2 $\dagger$ ).

The current densities for different alcohol oxidation processes are summarized in Fig. $4 \mathrm{a}$ and $\mathrm{b}$. The normalized iF (calculated using Pd mass) for the MOR $\left(\sim 4643 \mathrm{~mA} \mathrm{mg}^{-1}\right)$ was higher than for three other alcohols, i.e., it was $\sim 139, \sim 94$ and $\sim 26.5 \mathrm{~mA} \mathrm{mg}^{-1}$ for ethanol, 1-propanol and 2-propanol, respectively. The $\mathrm{iF} / \mathrm{iB}$ ratio for methanol is $\sim 12$ times higher than that for ethanol, $\sim 13$ times that for 1-propanol and $\sim 4$ times that for 2-propanol. The reactivity order for $\mathrm{Pd}-\mathrm{Cu} / \mathrm{C}$ is methanol $>$ ethanol $>$ 1-propanol $>$ 2-propanol. 2-Propanol electrooxidation showed a lower current density on a $\mathrm{Pd}-\mathrm{Cu} / \mathrm{C}$ electrode in alkaline medium, although $\mathrm{iF} / \mathrm{iB}$ is $\sim 5.4$. The negative shift in the onset of the ethanol oxidation reaction (EOR) suggested that a high copper content with very low amount of Pd was suitable for EOR kinetics using a $\mathrm{Pd}-\mathrm{Cu} / \mathrm{C}$ catalyst. The ethoxy $\left(\mathrm{CH}_{3} \mathrm{CO}\right)_{\text {ads }}$ was strongly adsorbed, and blocked hydrogen absorption/adsorption. The current intensity of iF increased due to the formation of fresh $\mathrm{Pd}-\mathrm{OH}$, through stripping carbonaceous residue from the electrode (eqn (11)$(14) \dagger)$. In addition, the increased current at high potentials sharply reached the largest value then started to decline, because a PdO layer formed on the electrode, blocking the further adsorption of reactive species. ${ }^{28}$ ATR-IR spectra (Fig. S9 $\dagger$ ) show the presence of $\mathrm{CO}_{2}$ and $\mathrm{CO}_{\text {ads }}$, whereas bands appear at $1670 \mathrm{~cm}^{-1}$ and $1390 \mathrm{~cm}^{-1}$ because of the formation of
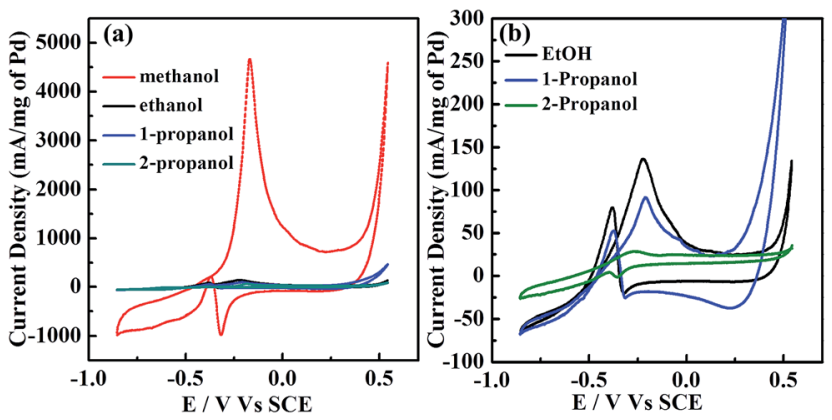

Fig. 4 (a) $\mathrm{CV}$ curves from: the $\mathrm{Pd}-\mathrm{Cu} / \mathrm{C}$ electrocatalyst for $\mathrm{C}_{1}-\mathrm{C}_{3}$ aliphatic alcohol (1 M) oxidation in $\mathrm{KOH}(1 \mathrm{M})$ solution; and (b) $\mathrm{Pd}-\mathrm{Cu}$ / $\mathrm{C}$ in $1 \mathrm{M} \mathrm{EtOH}$, 1-propanol and 2-propanol at a scan rate of $50 \mathrm{mV} \mathrm{s}^{-1}$ at room temperature. 
acetic acid. ${ }^{29}$ The $\mathrm{Pd}-\mathrm{Cu} / \mathrm{C}$ electrocatalyst has the potential to oxidize the intermediate to the final product, $\mathrm{CO}_{2}$, during EOR to some extent; $\mathrm{Cu}$ promotes oxidation through increasing the production of $\mathrm{OH}_{\mathrm{ads}}{ }^{-} / \mathrm{H}_{2} \mathrm{O}$ to eliminate the intermediate $\mathrm{CH}_{3}{ }^{-}$ $\mathrm{CO}_{\text {ads }}$ simultaneously on $\mathrm{Pd} .{ }^{30}$ The stability of $\mathrm{Pd}-\mathrm{Cu} / \mathrm{C}$ in all four alcohols (methanol, ethanol, 1-propanol and 2-propanol) was studied using chronoamperometry at a potential of $-0.25 \mathrm{~V}$, as shown in Fig. S2. $\dagger$ The slow current decay showed that the stability of the $\mathrm{Pd}-\mathrm{Cu} / \mathrm{C}$ electrocatalyst in methanol is best. Comparing the results, the current for methanol oxidation was higher than that for the other three alcohols. However, the oxidation currents from ethanol and 1-propanol were larger than that from 2-propanol. This suggested that $\mathrm{Pd}-\mathrm{Cu} / \mathrm{C}$ is less stable and shows lower anti-poisoning ability during 2-propanol oxidation in an alkaline medium.

During this oxidation, 1-propanol oxidizes to propanal first, and its further oxidation results in the formation of a stable product, propanoic acid (Scheme S1 $\dagger$ ). 1-Propanol is converted, with its carboxylate as the major product, as verified using ATRIR (Fig. S10 $\dagger$ ). 2-Propanol forms acetone as an intermediate product, leading to the poisoning of the electrode. ${ }^{31}$ ATR-IR spectra (Fig. S11 $\dagger$ ) of $\mathrm{Pd}-\mathrm{Cu} / \mathrm{C}$ also confirm that the electrocatalyst follows a dual pathway through acetone and propene intermediates to oxidize to $\mathrm{CO}_{2}$ finally (Scheme $\mathrm{S} 2 \dagger$ ). ${ }^{32-34}$ However, acetone formation is kinetically favored. ${ }^{35}$ The results show that the location of the $-\mathrm{OH}$ group in the alcohol influences the electrooxidation reaction kinetics. In contrast methanol oxidation using $\mathrm{Pd}-\mathrm{Cu} / \mathrm{C}$ has much higher catalytic activity than ethanol, 1-propanol and 2-propanol oxidation, which makes it a good candidate for direct methanol fuel cells.

In summary, we have first synthesized a bimetallic Pd-Cu NP loaded porous carbon material from a Cu-based MOF for alcohol electrooxidation. The $\mathrm{Cu}$ loaded porous carbon was presynthesized by calcinating the Cu-based MOF HKUST-1 under a $\mathrm{N}_{2}$ atmosphere. Afterwards, $\mathrm{Pd}-\mathrm{Cu} \mathrm{NP}$ loaded porous carbon was obtained for alcohol electrooxidation. Electrooxidation experiments revealed that $\mathrm{Pd}-\mathrm{Cu} / \mathrm{C}$ was suitable for steady state electrolysis for alcohol oxidation in alkaline media. In addition, different alcohols were electrooxidated using the present electrocatalyst to discuss the oxidation mechanism. This electrooxidation study of $\mathrm{Pd}-\mathrm{Cu} / \mathrm{C}$ derived from a MOF offers good understanding into the electrooxidation of different alcohols and it could provide useful guidance for the development of new electrocatalyst materials.

\section{Conflicts of interest}

There are no conflicts to declare.

\section{Acknowledgements}

The author S. M. would like to thank the CAS-TWAS President program. This work was supported by NSFC (21601189) and NSF of Fujian Province (2016J01085).

\section{References}

1 C.-J. Zhong, J. Luo, P. N. Njoki, D. Mott, B. Wanjala, R. Loukrakpam, S. Lim, L. Wang, B. Fang and Z. Xu, Energy Environ. Sci., 2008, 1, 454.

2 M. Jahan, Q. Bao and K. P. Loh, J. Am. Chem. Soc., 2012, 134, 6707.

3 (a) J. Lee, O. K. Farha, J. Roberts, K. A. Scheidt, S. T. Nguyen and J. T. Hupp, Chem. Soc. Rev., 2009, 38, 1450; (b) F. Luo, C. S. Yan, L. L. Dang, R. Krishna, W. Zhou, H. Wu, X. L. Dong, Y. Han, T. L. Hu, M. O'Keeffe, L. L. Wang, M. B. Luo, R. B. Lin and B. L. Chen, J. Am. Chem. Soc., 2016, 138, 5678.

4 (a) L. Shang, H. J. Yu, X. Huang, T. Bian, R. Shi, Y. F. Zhao, G. I. N. Waterhouse, L. Z. Wu, C. H. Tung and T. R. Zhang, Adv. Mater., 2016, 28, 1668; (b) A. Aijaz, J. Masa, C. Rosler, W. Xia, P. Weide, A. J. R. Botz, R. A. Fischer, W. Schuhmann and M. Muhler, Angew. Chem., Int. Ed., 2016, 55, 4087; (c) T. Wang, L. Shi, J. Tang, V. Malgras, S. Asahina, G. G. Liu, H. B. Zhang, X. G. Meng, K. Chang, J. P. He, O. Terasaki, Y. Yamauchi and J. H. Ye, Nanoscale, 2016, 8, 6712; (d) Z. G. Gu, D. X. Zhang, W. Q. Fu, Z. H. Fu, M. I. Vohra, L. Zhang, C. Woll and J. Zhang, Inorg. Chem., 2017, 56, 3526.

5 B. Liu, H. Shioyama, T. Akita and Q. Xu, J. Am. Chem. Soc., 2008, 130, 5390.

6 J. Tang and Y. Yamauchi, Nat. Chem., 2016, 8, 638.

7 S. Dang, Q.-L. Zhu and Q. Xu, Nat. Rev. Mater., 2017, 3, 17075.

8 M. E. Davis, Nature, 2002, 417, 813.

9 H. Wang, Q.-L. Zhu, R. Zou and Q. Xu, Chem, 2017, 2, 52.

10 (a) Y. J. Han, J. F. Zhai, L. L. Zhang and S. J. Dong, Nanoscale, 2016, 8, 1033; (b) M. H. Zhuang, X. W. Ou, Y. B. Dou, L. L. Zhang, Q. C. Zhang, R. Z. Wu, Y. Ding, M. H. Shao and Z. T. Luo, Nano Lett., 2016, 16, 4691.

11 (a) M. Xu, L. Han, Y. J. Han, Y. Yu, J. F. Zhai and S. J. Dong, J. Mater. Chem. A, 2015, 3, 21471; (b) X. Y. Gan, R. J. Zheng, T. L. Liu, J. Meng, R. P. Chen, X. Sun and X. Sun, Chem.Eur. J., 2017, 23, 7264.

12 W. Zhang, Z. Y. Wu, H. L. Jiang and S. H. Yu, J. Am. Chem. Soc., 2014, 136, 14385.

13 J. Li, Q. L. Zhu and Q. Xu, Chem. Commun., 2015, 51, 10827. 14 (a) S. T. Hunt, M. Milina, A. C. Alba-Rubio, C. H. Hendon, J. A. Dumesic and Y. Roman-Leshkov, Science, 2016, 352, 974; (b) C. Y. Song, D. M. Zhang, B. Wang, Z. Cai, P. Yan, Y. Sun, K. Ye, D. X. Cao, K. Cheng and G. L. Wang, Nano Res., 2016, 9, 3322.

15 Z. Yan, M. Zhang, J. Xie, J. Zhu and P. K. Shen, Appl. Catal., B, 2015, 165, 636.

16 B. Y. Xia, H. B. Wu, X. Wang and X. W. Lou, J. Am. Chem. Soc., 2012, 134, 13934.

17 J. Bagchi and S. K. Bhattacharya, Transition Met. Chem., 2007, 32, 47.

18 S. V. Myers, A. I. Frenkel and R. M. Crooks, Chem. Mater., 2009, 21, 4824.

19 P. S. Roy, J. Bagchi and S. K. Bhattacharya, Catal. Sci. Technol., 2012, 2, 2302. 
20 P. S. Roy and S. K. Bhattacharya, Catal. Sci. Technol., 2013, 3, 1314.

21 Y. Debauge, M. Abon, J. Bertolini, J. Massardier and A. Rochefort, Appl. Surf. Sci., 1995, 90, 15.

22 F. Delbecq, Surf. Sci., 1997, 389, L1131.

23 X. Xia, T. Iwasita, F. Ge and W. Vielstich, Electrochim. Acta, 1996, 41, 711.

24 J. S. Spendelow and A. Wieckowski, Phys. Chem. Chem. Phys., 2007, 9, 2654.

25 Y. X. Chen, A. Miki, S. Ye, H. Sakai and M. Osawa, J. Am. Chem. Soc., 2003, 125, 3680.

26 W. F. Lin, J. T. Wang and R. Savinell, J. Am. Chem. Soc., 1997, 144, 1917.

27 E. Batista, G. Malpass, A. Motheo and T. Iwasita, Electrochem. Commun., 2003, 5, 843.
28 A. Tripković, K. D. Popović and J. Lović, Electrochim. Acta, 2001, 46, 3163.

29 T. Iwasita and E. Pastor, Electrochim. Acta, 1994, 39, 531.

30 Q. Dong, Y. Zhao, X. Han, Y. Wang, M. Liu and Y. Li, Int. J. Hydrogen Energy, 2014, 39, 14669.

31 S.-G. Sun and Y. Lin, Electrochim. Acta, 1998, 44, 1153.

32 J. Otomo, X. Li, T. Kobayashi, C.-j. Wen, H. Nagamoto and H. Takahashi, J. Electroanal. Chem., 2004, 573, 99.

33 J. Ye, J. Liu, C. Xu, S. P. Jiang and Y. Tong, Electrochem. Commun., 2007, 9, 2760.

34 Y. Cheng, Y. Liu, D. Cao, G. Wang and Y. Gao, J. Power Sources, 2011, 196, 3124.

35 I. d. A. Rodrigues, J. P. I. De Souza, E. Pastor and F. C. Nart, Langmuir, 1997, 13, 6829. 